\title{
Development Tactic of Reformation System by Competitiveness of the Enterprise
}

\author{
Elena Alexsandrovna Nikitina ${ }^{1} \&$ Anatoly Andreevich Rudychev ${ }^{1}$ \\ ${ }^{1}$ Belgorod state technological University V. G. Shukhov, Russian Federation \\ Correspondence: Elena Alexsandrovna Nikitina, Kostyukova str., 46, Belgorod, 308012, Russian Federation.
}

Received: November 20, 2014 Accepted: December 26, 2014 Online Published: March 20, 2015

doi:10.5539/ass.v11n8p215 URL: http://dx.doi.org/10.5539/ass.v11n8p215

\begin{abstract}
To provide for an enterprise's own survival in the long-term, it is necessary for its goods (services) to be interesting to buyers to make them to give money for those, and also they should be more interesting to the buyers than the same or similar consumer quality products (services) manufactured by other companies.

Thus, managerial decisions with regard to production and sales of products should be based on full knowledge of market factors and taken with account of the impact that these decisions may have on the market. The results of this analysis have a direct impact on the adoption of an optimal decision associated with the following: formation of assortment programs; renewal of products; change in the specificity of the enterprise; change in the profile of production; ensuring timely sale of products; obtaining necessary investments for the development of production on beneficial terms, etc.
\end{abstract}

Keywords: competitiveness, management, reforming tactic

\section{Introduction}

Management of competitiveness is the strategic objective of any enterprise, the main one at marketing research of competitiveness, development and implementation of a comprehensive concept of competitiveness management.

An organizational and economic mechanism of support of competitiveness management is required, which would be based on target-oriented complex components reflecting the interdependence of organizational, economic, technical, and technological activities, the implementation of which contributes to the efficient implementation of managerial decisions in this field.

A reforming or improvement management system of an enterprise is possible due to changes in its characteristics or due to qualitative and quantitative modification of the control system.

The definition of all possible environmental factors caused by the unstable economic situation is succeeded by their selection to identify the most significant one. Thus, the use of any effective methods is possible - analytical, statistical, and economic-mathematical ones (Nikitina, 2013).

In developing the model of reforming the enterprise's management system in these conditions, the mechanism of considering the chosen factors on the enterprise and the management system during its reforming is needed. At the same time, the reforming process consists of changes in the components of the management system and its characteristics.

\section{Method}

The system analysis allows evaluating the whole set of factors determining the integral capacity of an enterprise and its competitiveness. But for the effective management of competitiveness of an enterprise, it is necessary to focus on a number of principles.

Orientation of the country's economy to market relations and rapid development of foreign economic relations determine the necessity of radical changes in the views on the management of production and create prerequisites for the development and implementation of methods of competitiveness management as the most powerful tool for elimination of controversies between customers' needs and capabilities of enterprises. Competitiveness wins a special status now, when foreign products that usually have much better quality than the domestic ones appear in the domestic market. 
Improvement of the situation in the market assumes radical improvement of the effectiveness of the economy through implementation of new production and management technologies focused on constant renewal of products and significant improvement of their quality. Today, therefore, considerable research efforts are directed to study the essence of competitiveness, the factors that affect its level, the methods of influence on it, as well as the tools of competitiveness management.

Competitiveness is systemic if its determinants can be understood only in case of interrelated exchange between the elements formed at different levels of the social system. Therefore, it is not sufficient to consider only the micro-level (enterprises, consumers, and market transactions) and the macro-level (trade and exchange rate, the state budget, and the foreign trade policy), which, of course, does not mean that these levels are less important. It is necessary to study the meta-level issues in order to understand why the state creates general conditions that are more or less favorable for the sustainable economic development, what role is played by different actors in the society at that, how the interaction of the state and non-state institutions takes place, and what goals of economic development are pursued in the course of this interaction, and the meso-level issues in order to analyze the measures that have a decisive influence on the performance of individual sectors and territories. The resulting model of the "systemic competitiveness" of the national economy includes four levels of analysis.

In order to form the system of evaluation of the enterprise competitiveness as the main activity lines of an enterprise and its main competitors, a clearly defined limited number of indicators can be selected. The list of the parameters used and the degree of their specification were defined by the following methodological assumptions.

Firstly, the number of evaluated characteristics should be rather limited in order to ensure the effectiveness of the adopted managerial decisions.

Secondly, because of the complexity and diversity of the problem and the lack of generally accepted approaches to the assessment of competitiveness, which requires extensive independent research, the proposed model uses the results obtained previously by domestic and foreign authors. The indicators were grouped based on the analysis of a wide range of problems of technical, economic, and social nature, which results in identifying the variables that provide for the competitiveness. The starting point of this analysis is to determine the list of technical and economic factors of competitiveness. A factor of competitiveness is the immediate cause, the presence of which is necessary and sufficient to change one or more criteria of competitiveness. The factors that are identified are the production, sales, service, and market factors, which reflect the influence of the internal and external environment on the enterprise.

During the reforming of the control system, an industrial enterprise in the conditions of the instability of the economic situation has to encounter with the following problems:

1) The impact of environmental factors, caused by economic instability, which are shown differently and can be differently estimated, must be considered.

2) The mechanism must be developed, with the help of which it would be possible to decide on the order of the reforming management system elements in the short-term, i.e. with the help of which it would be possible to develop the reforming tactics for the control system by an industrial enterprise.

For the solution of these problems, it is possible to use mathematical models and methods, and decision-making methods as the most promising ones (Belousov, 2008).

Decision-making in the real task management is a polysyllabic problem burdened by a variety of alternatives and existence of restrictions in opportunities of a person who has begun to make his decision.

Moreover, at analyzing the tasks, facing the control systems of industrial enterprises, it is possible to assert with confidence that all of them are of multicriteria nature. Even a simple statement about the achievement of the maximum economic benefit at minimum expenses already includes two criteria: the maximum profit and the minimum investment. In practice, it is necessary to link numerous operational tasks at the same time:

- Maximum profit;

- Maximum utilization of equipment;

- Maximum utilization of useful working time workers;

- Maximum demands;

- Maximum market share;

- Maximum profitability;

- Minimum cost; 
- Minimum stock of finished products;

- Minimum contingencies;

- Minimum order backlog;

- Minimum environmental pollution (Polzunova \& Kraev, 2006).

It is obvious that for the successful operation of an enterprise as a whole and the enterprise management system, in particular, it is necessary to adhere to such a methodology of reforming the system of enterprise management, which would promptly consider the negative manifestations of economic instability of the environment.

We believe that the main criterion for the process of reforming the enterprise management system under these conditions is to achieve the highest possible effectiveness of management.

V. I. Mukhin believes that the effectiveness of management (of control actions) is the degree of compliance of the (actual or expected) result to the required (desired) one or, in other words, the degree of the goal achievement. The degree of adaptation to the goal achievement was also concerned by V. S. Anfilatov.

The team of authors headed by Yu. V. Vasilyev expresses the view that "the effectiveness of management is a comparative characteristic of the operation effectiveness of a particular control system, which is reflected in various indicators of both the control object and the management activities (the subject of management), and these indicators can be both quantitative and qualitative".

Thus, effectiveness is a measure of implementation of functions of the system as a whole; the result of the system operation is the fact of implementation of these functions. The effectiveness of an enterprise operation is determined by how fully the market opportunities of the enterprise are identified and used with the maximum utilization of the potential in the work.

In the course of studying the issue of evaluation of the effectiveness of management systems, we identified the following main approaches to evaluating the effectiveness of the organizational management system:

1) The effectiveness of the management system is evaluated by the indicators characterizing the effectiveness of the enterprise performance. The full range of indicators that describe the financial and economic activities is analyzed.

2) Effectiveness of a management system is evaluated by a comprehensive indicator that combines characteristics of both the cost effectiveness of the management system and the production effectiveness. At that, the cost effectiveness of the management system (Es) is defined as the ratio of management costs to the value of fixed assets and working capital. The indicator of production effectiveness (Ep) is calculated as the ratio of labor productivity to the workforce. The general criterion of the management system effectiveness is the ratio Es/Ep.

3) The effectiveness of the management system is evaluated through an expert method, preferably using qualitative criteria, a set of which is rather versatile (expenses for the management apparatus, the general and specific objectives and functions of management, the organizational structure of management, the characteristics of the management process, the methods of management and development of managerial decisions, etc.).

4) Effectiveness of the management system is a function of the target $(R / T)$ and the resource $(R / C)$ effectiveness:

$$
E=f(R / T ; R / C)
$$

where $R$ is the result of the enterprise operation;

$T$ are the targets;

$C$ are the costs of the enterprise.

5) The effectiveness of the control system is evaluated using three interrelated groups of indicators:

- Resource effectiveness;

- Qualitative parameters characterizing the organization of the management process;

- Parameters characterizing the rationality of the organizational structure and its technical and organizational level.

6) The effectiveness of the control system is evaluated based on the resource-potential approach, according to which the level of use of the system's potential is taken into account.

The classical method of determining cost-effectiveness is based on the ratio of economic results to the cost of labor. As it is often difficult to provide direct assessment of the results in management, they apply indirect assessment that allows finding the share of the contribution of each employee in the final performance of the 
managerial staff:

$$
E=P_{m} / S
$$

where $E$ is the management effectiveness;

$P_{m}$ - performance of management;

$S$ - specific management costs.

In addition, there is a modification of this method for the analysis of the effectiveness of the collective managerial labor $\left(E_{c}\right)$ :

$$
E_{c}=V /\left(C_{l}+F_{r e v}+E F_{f a}\right)
$$

where $V$ is the volume of production, rubles;

$C_{l}$ are the labor costs of employees, rubles;

$F_{\text {rev }}$ are the operation costs for the revolving funds, rubles;

$F_{f a}$ is the cost of industrial fixed assets, rubles.

$E$ is the effectiveness coefficient with regard to the use of production assets.

7) From the perspective of the system analysis, all systems (including the enterprise management system) can be characterized based on the parameters of the material properties of the systems:

- The general system properties: integrity, stability, observability, controllability, determinacy, openness, dynamism, etc.;

- The structural properties: structure, coherence, organization, complexity, scale, spatial scale, centralization, volume, etc.

- The functional (behavioral) properties: efficiency, resource use, promptness, activity, power, mobility, productivity, execution speed, readiness, performance capability, accuracy, cost effectiveness, etc.

However, achieving the required level of effectiveness of the management system of an industrial enterprise in the current circumstances often becomes quite a complex problem.

As we have noted above, all of the construction materials industry enterprises in Russia, as a whole, and in the Belgorod Region, in particular, face certain difficulties. These negative phenomena were caused by external factors existing in the country. Because of the global crisis, stable economic relations between the whole sectors of the economy interconnected with various commodity-money relations were undermined.

The stability of the economy was broken; the economic crisis led to the so-called unstable economic situation. In addition, on the example of the construction materials industry enterprises, we can see the specific manifestations of market fluctuations, which can be treated as the stability disorder (the seasonal nature of demand, the emergence of substitute products).

To develop a methodology of the problem solution, we propose to resort to the system analysis.

System analysis is the most constructive line of system studies. At the same time, until now, the term "system analysis" is construed very broadly. It is known as a problem-solving methodology. In addition, system analysis is considered as the methodology for creating systems or improving a specific area of activity. Thus, the system analysis is a set of specific research methods and practical devices of solving various problems in all spheres of human activity based on the systematic approach and presentation of the object of study as a system. The system analysis is characterized by an orderly, logically substantiated approach to the study of problems and the use of existing methods for solving them, which could be developed in other sciences.

There are several approaches to solving problems using the system analysis. For their classification, we will expand the list compiled by V. N. Volkova and A. A. Denisov.

Thus, summarizing the stages of techniques of the system analysis, we can arrange them as follows:

1) Study of the problem's relevance.

2) Definition of goals that arise at solving the problem.

3) Decomposition of tasks assigned to solve the problem.

4) Synthesis of the key aspects of the problem solution.

5) Building the problem solution model. 
6) Implementation of the problem solution model.

7) Verification.

For this study, the solution of the following problem is relevant: reforming (or improving) the enterprise management system in the circumstances of economic instability in the optimal way. In view of the main provisions of the system analysis, the following mechanism to solve this problem is proposed:

1) Study of the relevance and assignment of goals of reforming the management system in the circumstances of the economic instability.

2) Decomposition of tasks arising at reforming the management system.

3) Synthesis of the key aspects of the problem solution.

4) Development and verification of the found model of the enterprise reforming.

When the goals for reforming of the management system are being set, the most relevant task is to improve its effectiveness.

\section{Results}

Let us consider application of the decision-making methods possible in these conditions. It should be noted that the tasks of decision-making are a rather numerous class of tasks encountered in many subject areas. Thus, the person who is responsible for the design and solution of this task must complete several stages of actions:

1) Prepare a set of admissible solutions.

2) Formulate goals of the decision-making.

3) Select the necessary decisions, which are optimal for achieving the decision-making goals.

In this case, we are inevitably confronted with the so-called multicriteria tasks, in which the relative importance of private criteria of optimality is considered (Nogalski, 2005).

The multicriteria task decision-making model can be represented as follows:

$$
\langle t, S, K, X, f, R, r\rangle
$$

where $t$ is the setting of the (type of) task;

$S$ is the set of solutions;

$K$ is the set of criteria;

$X$ is the variety scales of criteria;

$f$ is the mapping of the set of feasible solutions to the set of vector estimates;

$R$ is the system of preferences of the decision-maker;

$r$ is the decision rule.

The statement of the problem is consistent with the objectives of the decision-maker. The decision maker is understood as an individual (administrator, manager, engineer, designer) who seeks to formulate and solve the problem (i.e. make the necessary decisions) in a particular domain based on his perceptions of the importance of the parameters $x=\left(x_{1}, \ldots, x_{n}\right)$ and characteristics $y=\left(y_{1}, \ldots, y_{m}\right)$ of the described control system (Nikitina, 2013).

At the same time, we need to determine the concept of the mathematical model of a system, which means the dependence of the characteristics of a system $\left(y=\left(y_{1}, \ldots, y_{m}\right)\right)$ on its parameters $\left(x=\left(x_{1}, \ldots, x_{n}\right)\right)$ :

$$
\left\{\begin{array}{l}
y_{1}=y_{1}\left(x_{1}, \ldots, x_{n}\right), \\
\cdots \\
y_{m}=y_{m}\left(x_{1}, \ldots, x_{n}\right) .
\end{array}\right.
$$

Dependence can be described in various ways: analytical expressions, tables, algorithms, etc.

The set S represents a set of decisions, which satisfy each task to certain restrictions and are considered as possible ways of the goal achievement. The elements of the set $\mathrm{S}$ can also be named by versions of decisions, strategy, actions, alternatives, options, etc. (Russell \& Taylor, 2005)

In this case, each decision should lead to a specific outcome, the consequences of which are evaluated by criteria 
$\mathrm{K}_{1}, \mathrm{~K}_{2}, \ldots \mathrm{K}_{\mathrm{m}}$. In some tasks, the set of criteria can be set, but usually it is formed during the study of the assigned task.

The indicators admitting the decision-maker important with regard to the goal are called criteria. They are common for all admissible decisions and characterize the general value of decision, so that the decision-maker seeks to receive the most preferable estimates on them. Thus, they cannot be presented in the form of restrictions.

A scale should be built for each criterion, which scale represents a set of estimates with relation to the perfect order that has to be constructed. The scales $\tilde{O}_{1}, \tilde{O}_{2}, \ldots, \tilde{O}_{m}$, forming the set $\mathrm{X}$, can be numerical and non-numerical; numerical scales can be discrete and continuous. The set X may contain scales of various types.

The Cartesian product $Y=\tilde{O}_{1} \times \tilde{O}_{2} \times \ldots \times \tilde{O}_{m}$ forms a set of vector estimates. Each decision is estimated on scales $\tilde{O}_{1}, \tilde{O}_{2}, \ldots, \tilde{O}_{m}$, i.e. to find the admissible decisions, $\mathrm{S}$ is put in compliance with the set of the admissible vector estimates $A \subseteq Y$ by mapping $f: S \rightarrow A$.

In the decision theory, it is assumed that each decision-maker has a system of preferences, which should be for rational action. The system preferences of a decision-maker are understood as a set of his structured representations associated with the advantages and disadvantages of the compared solutions (Worthington, 2010).

Stages of solution of multicriteria tasks can be presented as the algorithm shown in Figure 1.

Specifically in our case, there is a task of tactical (operational) reforming of the elements of the control system of an industrial enterprise in the circumstances of instability (Shchetinina \& Polarus, 2012). The set of alternatives will be represented by separate elements of a control system, the set of criteria - by the factors of environment reflecting the influence of the economic instability. Graphically, the stages of our multiobjective task are presented in Figure 1.

Currently, there are several approaches to solving multiobjective problems:

1) The abstract model of choice of the multiscale extreme mechanisms that allow for a rational choice with respect to the vector criterion.

2) Application of the theory of utility for the multicriteria selection of a discrete set of alternatives in the circumstances of risk and uncertainty.

3) The decision based on the set of axioms established in advance.

4) The converting multi-criteria choice task of scalar optimization with vector convolution of criteria.

5) Construction of an area of compromises and its corresponding set of Pareto-optimum decisions for some classes of multicriteria optimization tasks.

\section{Discussion}

Analyzing the characteristics of the enterprise management, we should allocate a number of the so-called criteria or properties, which the chosen method of the solution of set multicriteria task should have, in our opinion (6). Firstly, it must conform to the course of human thought. Thus, mathematical bases laid in it should not replace the human mind and experience in interpretation of the real world. Secondly, the method must take into account the fact that, as a rule, there are many opinions, many styles of decision-making. In the process of developing a uniform solution the conflicts are possible. Therefore, mechanisms of consent achievement are necessary (Snitko, Alyabyeva, \& Dotsenko, 2011). The method must take into account the fact that often (especially for scale tasks) there are multiple solutions. As a result, unsystematic decision-making process brings uncertainty, affecting the quality of decisions. Besides, it is not always possible to build a logical chain of reasoning, when it is possible to choose only one of two options and compromises are not admissible, and to choose the best solution. Therefore, the mechanism of quantitative ranking (prioritization) for possible solutions is needed to ensure clarity (Problems and Trends of Economy, 2012). 


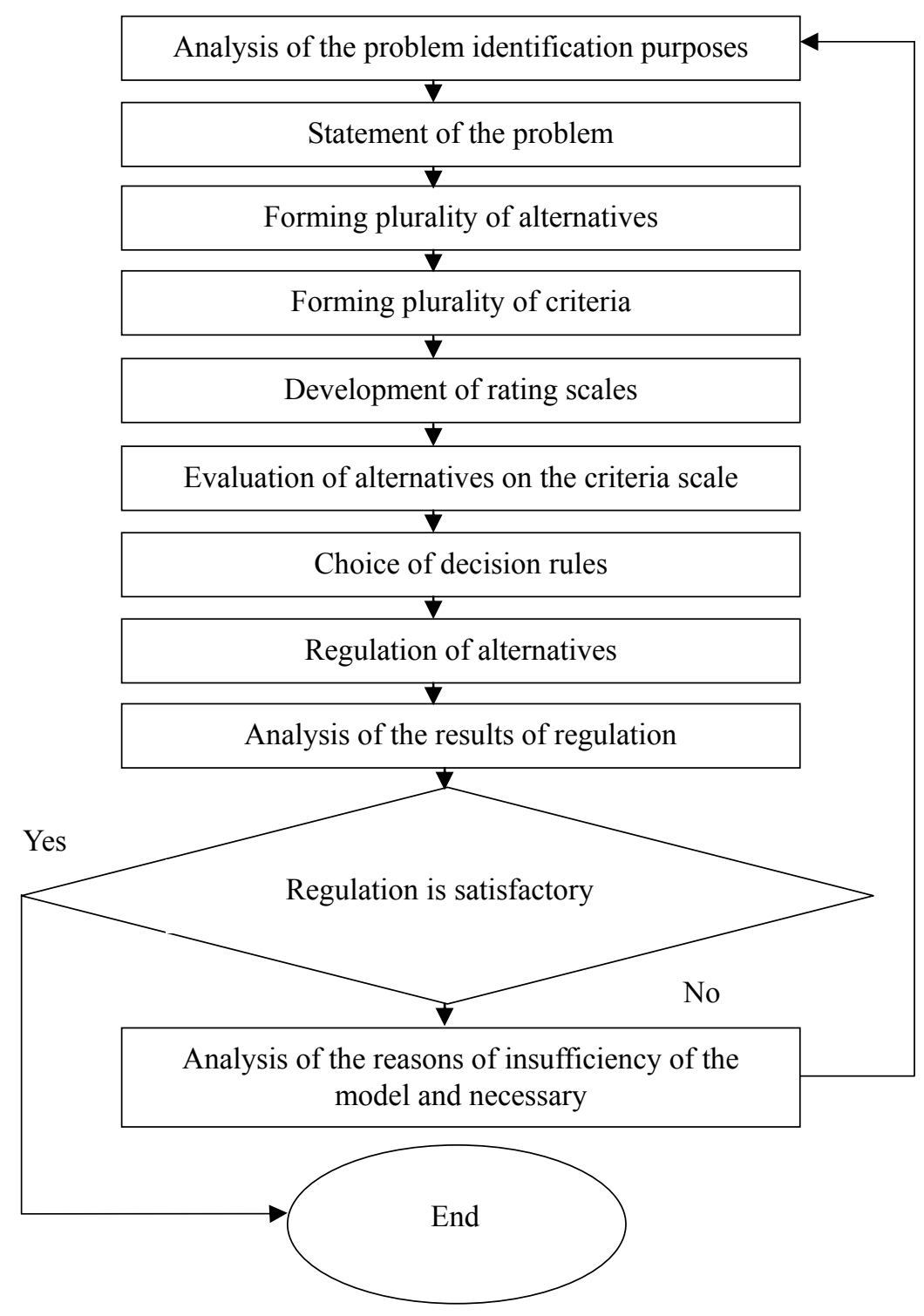

Figure 1. Stages of solution of multicriteria tasks

Also, the method should serve as a universal basis for systematic decision-making, allowing to make a cottage industry out of the decision-making process. (Instead of the brainstorming organized spontaneously and without a clear plan, we obtain a clear algorithm of organizations' reflecting over decision-making in any field of activity) (Gorbashko \& Maksimtsev, 2014). The method must assume reasonable and comprehensible way of rating possible decisions. Otherwise the process of decision-making may be uncertain, and potential opportunities can be lost. The method must take into account both available quantitative information, and qualitative information about the preferences of decision-makers (like - not like, better - worse, etc.), that is extremely important for the economy, the policy, the management, and the social sphere. In this regard, the procedure of paired comparisons can be useful.

\section{Conclusion}

One of the promising methods for solving multicriteria problems (satisfying circumstances to above) is, also called, analytic hierarchy method. The analytic hierarchy method is a tool of the system approach to solution of the complex problems of decision-making. This method was developed by R. Bellman, B. N. Brooke, V. N. Burkov (Bertsekas, 2007). The method became very popular after publication of the works by T. Saati who called this procedure the method of analytic hierarchy (MAH) (Bichoyeva, 2011). T. Saati's publications opened the great capacity of the MAH at solving various tasks of both theoretical and practical nature. 


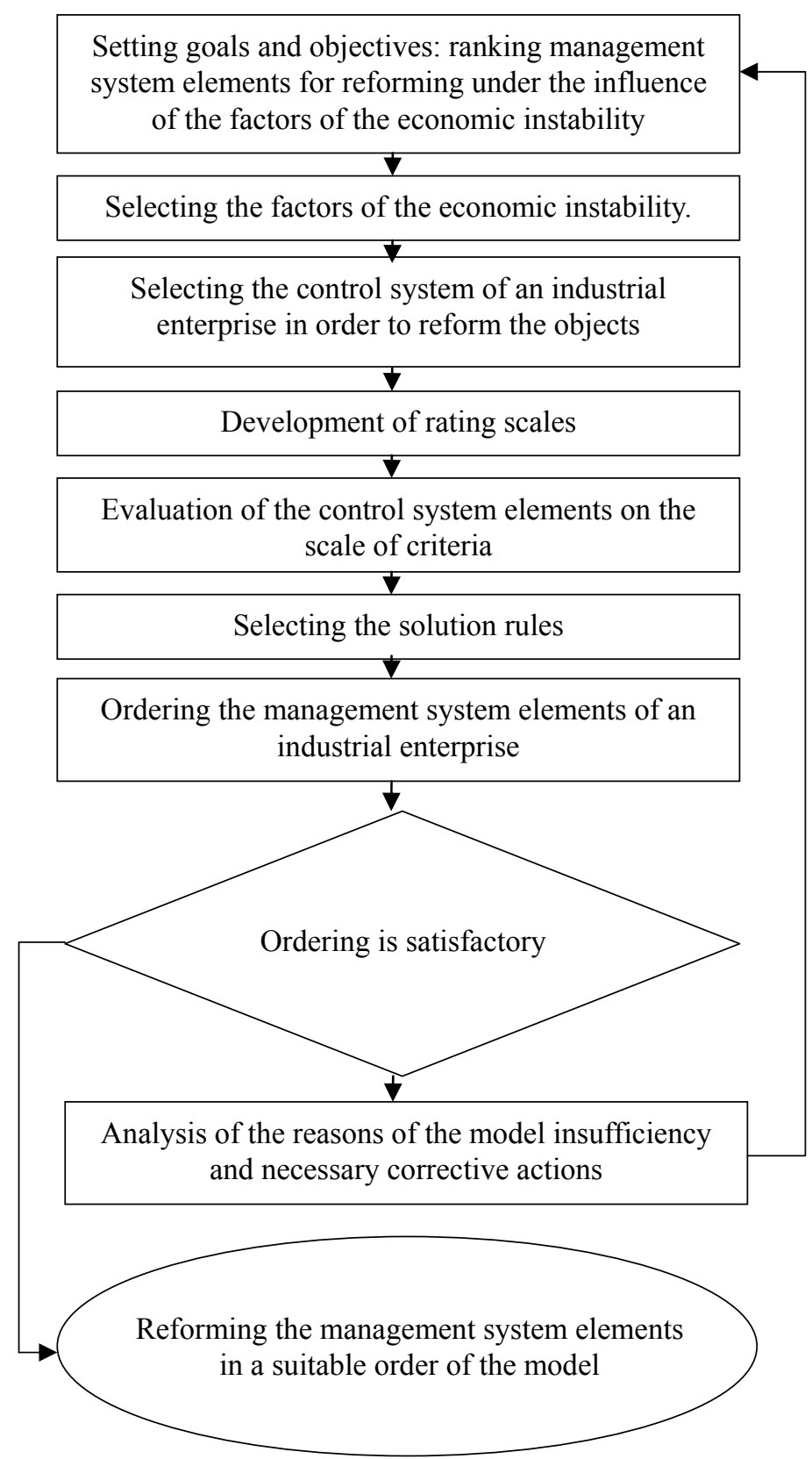

Figure 2. Steps for solving the problem of formation tactics of reforming the management system of an industrial enterprise

The peculiarity of the MAH is that it does not offer the person who is making a decision (decision-maker) a "correct" decision, and allows him to find in an interactive mode such an option (alternative), which best conforms to his understanding of the nature of the problem and requirements to its solution. Along with the math, it is based on psychological aspects (Rudychev, Nikitina, \& Levchenko, 2013). MAH allows clearly and rationally structuring a thorny problem of making decision as a hierarchy, comparing and performing quantitative assessment of alternative options of the decision (Roberts, 1965). The analytic hierarchy method used worldwide for making decision in a variety of situations: from management at the State level to solve industry specific problems and in business, industry, health and education (Chizova, 2002). The computer support of MAH is ensured with software products developed by various companies. The analysis of the problem of making decisions in MAH begins with building a hierarchical structure, which includes the purpose, the criteria, the alternatives and considers other factors influencing the choice (Feldman \& Audretsch, 1999). Each element of the hierarchy can represent various aspects of the task to be solved; moreover, both material and intangible factors, measured quantitative and qualitative characteristics, objective data and subjective expert 
judgment can be taken into account (Porter, 1998). In other words, the analysis situation of choosing a decision with MAH reminds of the procedures and argumentation's methods, which are used at the intuitive level. The next step of the analysis is the definition of priorities, representing the relative importance or preference of elements of constructed hierarchical structure, using the procedure of pair comparisons. The dimensionless priorities allow comparing diverse factors reasonably, which is a distinctive feature of MAH (European Commission, 2002). At the final stage of the analysis, the synthesis (linear convolution) of priorities in the hierarchy takes place, in which priorities of alternative solutions are calculated concerning the main objectives. The alternative with the highest priority value is considered the best one.

\section{Acknowledgments}

The article was prepared within the framework of the budget-funded Scientific-Research Work No.1623, the base part of the state task of the Russia Ministry of Education.

\section{References}

Belousov, V. V. (2008). Management of Competitiveness of the Industrial Enterprise. Izvestia of the Russian state pedagogical university named after A. I. Herzen, 85, 321-323.

Bertsekas, D. P. (2007). Dynamic Programming and Optimal Control (p. 1270). Athena Scientific.

Bichoyeva, D. S. (2011). Competitiveness of Consumer Goods and Services and its Dependence on the Competitiveness of the Entrepreneurial Undertakings as a whole. Current Issues of the Economy and Law, 3, 66-71.

Chizova, E. N. (2002). Rationalization of Activity of the Enterprise: Monograph (p. 342). Saint Petersburg: Khimizdat.

Competitiveness and Business Environment in Finland - an International Benchmarking. (2004). Ministry of Trade and Industry of Finland.

European Commission. (2002) Productivity: The Key to Competitiveness of European Economies and Enterprises. Communication from the Commission to the Council and the European Parliament, Brussels, $\operatorname{COM}(2002)$ 262, 21.5.2002.

Feldman, V. P., \& Audretsch, D. B. (1999). Innovation in Cities: Science based Diversity, Specialization and Localized Competition. European Economic Review, 43, 409. http://dx.doi.org/10.1016/S0014-2921 (98)00047-6

Gorbashko, E. A., \& Maksimtsev, E. A. (2014). Management of competitiveness. Theory and practice (p. 448). Moscow: Urait.

Nikitina, E. A. (2013). Correlation of the Competitiveness of the Enterprise and Competitiveness Goods. Bulletin of BSTU, 4, 125-129.

Nikitina, E. A. (2013). Economic Maintenance of Competitiveness of the Enterprise. In the Proceedings of the $3^{\text {rd }}$ Intenational Conference "Law, Economy and Management in Modern Ambiance" (pp. 745-752), Serbia, Belgrade.

Nogalski, B., \& Valentinovich, P. (2005). Application of new Concepts of Management at the Industrial Enterprises of Poland. Russian Management Journal, 3(3), 149-156.

Polzunova, N. N., \& Kraev, V. N. (2006). The Study of Control Systems (p. 240). Moscow: Academic Avenue; Trixta.

Porter, M. E. (1998). Competitive Advantage (p. 580). The Free Press.

Problems and Trends of Economy and Management in the Modern World. (2012). In the Proceedings of the 2012 International Conference, Bulgaria, Sofia.

Roberts, S. (1965). Dynamic programming processes in chemical technology and management methods (p. 480). Moscow: Mir.

Rudychev, A. A., Nikitina, E. A., \& Levchenko, A. S. (2013). To the Question about Basic Directions of Enterprise Competitiveness Increase at the Branch Level. World Applied Sciences Journal, 24(12), 1707-1710.

Russell, R. S., \& Taylor, B. W. (2005). Operations Management: Quality and Competitiveness in a Global Environment (p. 832). Wiley. 
Shchetinina, D. U., \& Polarus, A. V. (2012). Methodological Approaches to the Assessment of the Communications Potential of the Industrial Enterprise. Bulletin of the V. G. Shukhov University, 3, 133-136

Sntko, L. T., Alyabyeva, M. V., \& Dotsenko, A. N. (2011). Economy of an Enterprise. International Journal of Experimental Education, 12, 84-85.

Worthington, S., Russel-Bennet, R., \& Hartel, C. (2010). A Tri-Dimensional Approach for Auditing Brand Loyalty. Journal of Brand Management, 17, 243-253. http://dx.doi.org/10.1057/bm.2009.24

\section{Copyrights}

Copyright for this article is retained by the author(s), with first publication rights granted to the journal.

This is an open-access article distributed under the terms and conditions of the Creative Commons Attribution license (http://creativecommons.org/licenses/by/3.0/). 